\title{
Extremity doses of nuclear medicine personnel: a concern
}

\author{
Gerrit J. Kemerink • Filip Vanhavere • Ilona Barth • \\ Felix M. Mottaghy
}

Published online: 15 November 2011

(C) The Author(s) 2011. This article is published with open access at Springerlink.com

\section{Introduction}

Nearly one in five workers in nuclear medicine is likely to receive more than the legal dose limit for the skin of $500 \mathrm{mSv}$ per year according to a recently completed ORAMED study [1, 2]. ORAMED (Optimization of RAdiation protection of MEDical staff) was a European FP7 project which aimed to develop methodologies for better assessing and reducing the exposure to radiation of personnel working in interventional radiology and cardiology and nuclear medicine. One of the goals of the project was to determine extremity doses of workers in nuclear medicine during the preparation and administration of radiopharmaceuticals. Six countries participated in the study, and large

\section{G. J. Kemerink $(\bowtie) \cdot$ F. M. Mottaghy \\ Department of Nuclear Medicine, \\ Maastricht University Medical Center, \\ P. Debyelaan 25, \\ 6229HX Maastricht, The Netherlands \\ e-mail: gerrit.kemerink@mumc.nl}

\section{G. J. Kemerink}

Department of Radiology, Maastricht University Medical Center, Maastricht, The Netherlands

\section{F. Vanhavere}

Belgian Nuclear Research Centre SCK*CEN,

Mol, Belgium

\section{Barth}

Department of Radiation Protection and Health,

Federal Office for Radiation Protection (BfS),

Berlin, Germany

F. M. Mottaghy

Department of Nuclear Medicine,

University Hospital RWTH Aachen,

Aachen, Germany numbers of procedures using ${ }^{99 \mathrm{~m}} \mathrm{Tc}(n=335),{ }^{18} \mathrm{~F}(n=306)$ and ${ }^{90} \mathrm{Y}(n=127)$ were monitored.

In stark contrast with the finding of too high extremity doses is the general lack of attention in nuclear medicine paid to extremity dosimetry. The main purpose of this contribution is therefore to emphasize that extremity exposure is a real concern needing the attention of the professional societies and the technical and medical staff. In addition, some guidance is provided in measuring and lowering the extremity dose.

\section{Risks of commonly used radionuclides}

The ORAMED project $[1,2]$ considered ${ }^{99 \mathrm{~m}} \mathrm{Tc},{ }^{18} \mathrm{~F}$ and ${ }^{90} \mathrm{Y}$, but did not include ${ }^{68} \mathrm{Ga}$ and ${ }^{124} \mathrm{I}$. The latter two nuclides are increasingly used in PET and they have relatively unfavourable risk profiles. Here we consider all five radionuclides. Their basic physical characteristics are summarized in Tables 1 and 2 [3-5]; some of these are briefly discussed to illustrate the relative radiation hazards of the nuclides.

According to Table 1, the $511 \mathrm{keV}$ annihilation radiation of ${ }^{18} \mathrm{~F}$ and ${ }^{68} \mathrm{Ga}$ causes a nearly eightfold higher wholebody dose than the $141 \mathrm{keV}$ gamma photons from ${ }^{99 \mathrm{~m}} \mathrm{Tc}$ [3]. This is a result of the higher energy of the annihilation radiation $(511 \mathrm{keV}$ versus $141 \mathrm{keV})$ and the formation of two $511 \mathrm{keV}$ photons per decay of these positron emitters, whereas ${ }^{99 \mathrm{~m}} \mathrm{Tc}$ emits only one photon per decay. Betaminus, positron and electron particles emitted by the commonly used nuclides do not directly contribute to the body dose as this is measured at a depth of $10 \mathrm{~mm}$ which is too deep for these particles to reach.

When positrons are not completely stopped, e.g. by the liquid in which they are present or the material surrounding the activity, they contribute to the skin dose. In the case of 
Table 1 Exposure parameters of some radionuclides [3, 4]

\begin{tabular}{|c|c|c|c|c|c|}
\hline \multirow[t]{2}{*}{ Nuclide } & \multirow{2}{*}{$\begin{array}{l}\text { Body dose }^{a} \text { due to } \\
\text { point source in air } \\
{\left[\mathrm{mSv} \cdot \mathrm{m}^{2} /(\mathrm{GBq} \cdot \mathrm{h})\right]}\end{array}$} & \multirow{2}{*}{$\begin{array}{l}\text { Skin dose }{ }^{\mathrm{b}} \text { due to } \\
\text { contact with } 5 \text {-ml syringe } \\
{[\mathrm{mSv} /(\mathrm{MBq} . \mathrm{h})]}\end{array}$} & \multirow{2}{*}{$\begin{array}{l}\text { Skin dose }{ }^{\mathrm{b}} \text { due to } \\
\text { contamination with } \\
50 \mu \mathrm{l} \text { on } 1 \mathrm{~cm}^{2} \\
{[\mathrm{mSv} /(\mathrm{kBq} \cdot \mathrm{h})]}\end{array}$} & \multicolumn{2}{|c|}{ Lead shielding (mm) } \\
\hline & & & & $\begin{array}{l}\text { To lower } \\
\text { transmission } \\
\text { to one-half }\end{array}$ & $\begin{array}{l}\text { To lower } \\
\text { transmission } \\
\text { to one-tenth }\end{array}$ \\
\hline${ }^{99 \mathrm{~m}} \mathrm{Tc}$ & 0.02168 & 0.354 & 0.00877 & 0.3 & 1 \\
\hline${ }^{18} \mathrm{~F}$ & 0.1655 & 2.88 & 0.788 & 6 & 17 \\
\hline${ }^{68} \mathrm{Ga}$ & 0.1580 & 31.4 & 1.25 & 6 & 17 \\
\hline${ }^{124} \mathrm{I}$ & 0.1745 & 10.7 & 0.36 & 8 & 31 \\
\hline${ }^{90} \mathrm{Y}$ & 0 & 43.5 & 1.35 & \multicolumn{2}{|c|}{ Total $\beta$-absorption in $9.2 \mathrm{~mm}$ plastic } \\
\hline
\end{tabular}

${ }^{a}$ Strictly ambient dose equivalent, $H^{*}(10)$, effectively due to gamma radiation.

${ }^{\mathrm{b}}$ Personal dose equivalent, $\mathrm{Hp}(0.07)$, in principle due to electrons, beta and gamma radiation

point sources of ${ }^{18} \mathrm{~F},{ }^{68} \mathrm{Ga}$ and ${ }^{124} \mathrm{I}$ in air, at a distance of $30 \mathrm{~cm}$, the positron contribution to the skin dose is about 66,60 an 13 times the contribution of gamma radiation, respectively [4]. This shows that radiation protection of the skin against PET nuclides should in the first place be directed at stopping the positrons.

For bare 5-ml syringes held with the fingers, the skin doses for ${ }^{18} \mathrm{~F},{ }^{68} \mathrm{Ga}$ and ${ }^{124} \mathrm{I}$ are 8, 89 and 30 times higher than for ${ }^{99 \mathrm{~m}} \mathrm{Tc}$, respectively [4]. Note that positrons from ${ }^{18} \mathrm{~F}$ have a lower energy (and range) than those of ${ }^{68} \mathrm{Ga}$ and ${ }^{124} \mathrm{I}$, and many more of them are therefore stopped in the syringe and do not contribute to the skin dose. A 5-ml syringe with $1 \mathrm{GBq}$ of ${ }^{68} \mathrm{Ga}$ causes a skin dose rate of $8.7 \mathrm{mSv} / \mathrm{s}$, which means that the annual dose limit of $500 \mathrm{mSv}$ would be reached in less than $1 \mathrm{~min}$ of contact. For such high-energy positron emitters in a syringe or vial the contribution of positrons to the skin dose is dominant, and protection against these positrons should again be the first goal.

In the case of skin contamination, the ratios of the skin doses with respect to ${ }^{99 \mathrm{~m}} \mathrm{Tc}$ are 90,143 and 41 (Table 1). In this situation also for ${ }^{18} \mathrm{~F}$ only a few positrons are stopped in the very thin source forming the contamination.

Table 2 Some radionuclides and their decay properties relevant to occupational exposure [5]

\begin{tabular}{lll}
\hline Nuclide & $\begin{array}{l}\text { Energy gamma } \\
\text { (intensity) } \\
{[\mathrm{keV},(\text { per decay) }]}\end{array}$ & $\begin{array}{l}\text { Maximum energy beta } \\
\text { particle (intensity) } \\
{[\mathrm{keV}, \text { (per decay) }]}\end{array}$ \\
\hline${ }^{99 \mathrm{~m}} \mathrm{Tc}$ & $141(89 \%)$ & - \\
${ }^{18} \mathrm{~F}$ & $511(193 \%)$ & $634(97 \%)$ \\
${ }^{68} \mathrm{Ga}$ & $511(178 \%)$ & $1,899(88 \%)$ \\
${ }^{124} \mathrm{I}$ & $511(45 \%), 603(63 \%)$, & $1,535(12 \%), 2,138(11 \%)$ \\
${ }^{90} \mathrm{Y}$ & $723(10 \%)$ & $2,284(100 \%)$ \\
\hline
\end{tabular}

The $511 \mathrm{keV}$ gammas originate from positron annihilation; their intensity is taken as two times the positron intensity, assuming local annihilation
The beta-minus emitter ${ }^{90} \mathrm{Y}$ is extensively used in therapy. It has a high maximum beta energy (Table 2) causing many beta particles to escape from a vial or syringe, resulting in a high skin dose from holding a bare container $(12 \mathrm{mSv} / \mathrm{s}$ for a 5-ml syringe containing $1 \mathrm{GBq})$. Note that this is only slightly higher than for ${ }^{68} \mathrm{Ga}(8.7 \mathrm{mSv} / \mathrm{s}$ per $\mathrm{GBq}$, a value dominated by the contribution of positrons). In other words, a high-energy positron emitter such as ${ }^{68} \mathrm{Ga}$ combines the risks of ${ }^{18} \mathrm{~F}$ as far as annihilation radiation is concerned and (nearly) the risk of ${ }^{90} \mathrm{Y}$ as far as positrons are concerned.

In conclusion, these considerations show that the risk of an elevated skin dose is much higher for the beta (beta-minus and positron) emitters considered here than for ${ }^{99 \mathrm{~m}} \mathrm{Tc}$, the nuclide many workers in nuclear medicine first encountered.

\section{Data on extremity dose}

When handling unsealed radiopharmaceuticals, the skin of the hands of nuclear medicine personnel is the organ most at risk. The ICRP has recommended that the personal dose equivalent $\mathrm{Hp}(0.07)$, the dose at a depth of $0.07 \mathrm{~mm}$, be used as a measurable proxy for the equivalent skin dose [6]. The annual dose limit of $500 \mathrm{mSv}$ applies to the average over the single square centimetre with the highest exposure [6].

Assessment of compliance with the skin dose limit of $500 \mathrm{mSv} /$ year is difficult in practice as the area with the highest exposure has to be monitored. This location is not known in advance, and it can vary from procedure to procedure, but most often it is the tip of one of the fingers or the thumb $[1,2]$. Unfortunately, it is not practical to put a dosimeter at the tip of a digit, as this would affect the digit's use, and also because the fragile dosimeter would easily fracture. Furthermore, the dose must be measured at the tissue depth equivalent to $0.07 \mathrm{~mm}$. This is not trivial for beta particles and positrons, because it requires very thin detectors with thin covers. So far extremity dosimetry has 
mostly been performed using ring finger or wrist dosimeters, which has been found to result in severe underestimation of the extremity dose $[1,2]$. Even worse, in most hospitals extremity dosimetry is not being performed at all.

We only mention the most relevant findings from the ORAMED study; for the complete results we refer to the website [1] and publications [2]. In the study, detailed doses were measured on the fingers, thumb and wrist using thin $\mathrm{LiF}: \mathrm{Mg}, \mathrm{Cu}, \mathrm{P}$ thermoluminescence dosimeters. The measurements were complemented by Monte Carlo simulations. For all procedures, in diagnostics as well as in therapy, the difference between minimum and maximum extremity doses was huge, as is illustrated by Table 3. Evidently bad practices were also observed, e.g. holding bare vials and syringes with the fingers. The authors estimated that between $15 \%$ and $20 \%$ of those working with both ${ }^{99 \mathrm{~m}} \mathrm{Tc}$ and ${ }^{18} \mathrm{~F}$ may exceed the annual skin dose limit of $500 \mathrm{mSv}$. Similar finger doses have been reported by Covens et al. [7] in a review and by Rimpler and Barth [8].

For ${ }^{124} \mathrm{I}$, the highest skin dose (on the thumb) measured for preparation was $9.5,3.1$ and $1.0 \mathrm{mSv} / \mathrm{GBq}$, depending on the degree of optimization of the procedure [9]. However, the first method was already rather well optimized, and much higher skin doses will be incurred if protection is poor. For ${ }^{68} \mathrm{Ga}$ no experimental data are available as far as we know.

The ORAMED study paid special attention to the estimation of the maximum skin dose in daily practice. For all three nuclides studied the authors concluded that the dose measured by a ring dosimeter with the detector on the palmar base of the forefinger of the nondominant hand gave an acceptable estimate of the maximum skin dose, provided a correction factor of about 6 was applied.

Covens et al. also investigated skin contamination (this work is also presented in reference [1]). Of the 300 procedures monitored, $9 \%$ revealed a contamination, while

Table 3 Maximum skin doses of both hands in nuclear medicine procedures measured within the ORAMED project $[1,2]$

\begin{tabular}{llll}
\hline Procedure & \multicolumn{3}{l}{ Skin dose $(\mu \mathrm{Sv} / \mathrm{GBq})$} \\
\cline { 2 - 4 } & Mean & Minimum & Maximum \\
\hline${ }^{99 \mathrm{~m}} \mathrm{Tc}$ preparation & 432 & 33 & 2,062 \\
${ }^{99 \mathrm{~m}} \mathrm{Tc}$ administration & 233 & 12 & 951 \\
${ }^{18} \mathrm{~F}$ preparation & 1,205 & 97 & 4,433 \\
${ }^{18} \mathrm{~F}$ administration & 933 & 139 & 4,113 \\
${ }^{90} \mathrm{Y}$ DOTATOC preparation & 2,100 & 100 & 7,400 \\
${ }^{90} \mathrm{Y}$ DOTATOC administration & 1,900 & 400 & 4,900 \\
${ }^{90} \mathrm{Y}$ Zevalin preparation & 11,000 & 700 & 63,700 \\
${ }^{90} \mathrm{Y}$ Zevalin administration & 4,800 & 700 & 24,600 \\
\hline
\end{tabular}

all workers were unaware of it. Skin doses up to $30 \mathrm{mSv}$ due to a single contamination were estimated.

\section{Shielding}

The differences in gamma radiation emitted by ${ }^{99 \mathrm{~m}} \mathrm{Tc},{ }^{18} \mathrm{~F}$, ${ }^{68} \mathrm{Ga}$ and ${ }^{124} \mathrm{I}$ also affect shielding requirements, as is illustrated in Table 1. Shielding should be used whenever possible and it should be adapted to the radionuclide that is being handled. The ORAMED study assessed the benefit of shielding using Monte Carlo simulations. For ${ }^{99 \mathrm{~m}} \mathrm{Tc}$, shielding with $2 \mathrm{~mm}$ tungsten or lead should usually be sufficient. For ${ }^{18} \mathrm{~F}$, syringe shields of tungsten (or lead) of $5 \mathrm{~mm}$ or preferably $8 \mathrm{~mm}$ thickness should be used. For ${ }^{90} \mathrm{Y}$, shielding with tungsten is best, as a shield of $5 \mathrm{~mm}$ tungsten has been shown to give better protection than $10 \mathrm{~mm}$ acrylic in recent studies [10-12]. For syringes with less than $200-300 \mathrm{MBq}{ }^{90} \mathrm{Y}$ the cheaper acrylic is satisfactory, however. The studies [10-12] also indicate that a shield of just tungsten is the best choice for the highenergy positron emitters ${ }^{68} \mathrm{Ga}$ and ${ }^{124} \mathrm{I}$, as it both stops the positrons and attenuates the gamma radiation and bremsstrahlung. However, syringe shields do not provide protection near the syringe bottom.

\section{Conclusions}

Radiation exposure of the hands of personnel in nuclear medicine is a real concern and needs to be addressed urgently. The high doses, and the large spread of doses, are most likely due to lack of radiation awareness and optimization. Some recommendations can be formulated:

1. Professional societies should address extremity dosimetry at their meetings to disseminate information on radiation risks and how these risks can be countered.

2. Technical and medical staff have to take responsibility for their personnel by improving awareness of the existing risks, and by providing education and training. Educational material developed as part of the ORAMED project [1], or available at the IAEA [13], may be helpful.

3. Extremity doses should routinely be measured with a ring dosimeter suitable for beta and gamma radiation, worn on the palmar side of the proximal phalanx of the forefinger of the nondominant hand. A correction factor of 6 should be applied to obtain an estimate of the actual maximum skin dose. The use of dosimeters worn on the ring finger or on the wrist should be discontinued.

4. Performing a study within the workers' own department, aiming at the optimization of a procedure used in 
the preparation and administration of activity for imaging or therapy, is an excellent way to achieve radiation awareness, to educate and train workers, and to show compliance with dose limits.

5. Working with positron emitters, especially with highenergy ones, should only be initiated after adequate education and training of workers.

6. Frequent checks for contamination should be performed during all handling of radioactivity.

7. Sufficient shielding materials should be provided for all stages of handling activity where skin exposure is possible. In addition, suitable forceps, pincers, tweezers and possibly other equipment should be available to keep activity at a distance while handling it. Using automated systems may also help.

8. Direct contact of the fingers with unshielded vials, syringes, tubing or valves containing radionuclides must be avoided. This should become a basic principle when handling beta emitters.

Finally, an important and reassuring conclusion from the ORAMED project and the ${ }^{124}$ I study [9] is that acceptable levels of radiation exposure can be achieved when workers are trained and procedures have been optimized.

Open Access This article is distributed under the terms of the Creative Commons Attribution Noncommercial License which permits any noncommercial use, distribution, and reproduction in any medium, provided the original author(s) and source are credited.

\section{References}

1. Belgian Nuclear Research Centre $(\mathrm{SCK} \cdot \mathrm{CEN})$, Optimization of Radiation Protection of Medical Staff.http://www.oramed-fp7.eu/ en/Presentations. Accessed 27 Oct 2011
2. Radiation Measurements, Volume 46 Issue 11; Special Issue: International Workshop on Optimization of radiation Protection of Medical Staff, ORAMED 2011.

3. Tschurlovits M, Leitner A, Daverda G. Dose rate constants for new dose quantities. Radiat Prot Dosimetry. 1992;42:77-82.

4. Delacroix D, Guerre JP, Leblanc P, Hickman C. Radionuclide and radiation protection data handbook 2002. Radiat Prot Dosimetry. 2002;98:1-168.

5. National Nuclear Data Center (NNDC). Evaluated Nuclear Structure Data File (ENSDF), Brookhaven: National Nuclear Data Center (NNDC). http://www.nndc.bnl.gov/chart/decaysearchdirect.jsp? nuc $=124 \mathrm{I} \& u n c=$ nds. Accessed 27 Oct 2011 (note the nuclide ${ }^{90} \mathrm{Y}$ instead of ${ }^{124} \mathrm{I}$ is for instance chosen by replacing " $124 \mathrm{I}$ " by " $90 \mathrm{Y}$ ").

6. International Commission on Radiological Protection. ICRP Publication 103: Recommendations of the ICRP. Annals of the ICRP, vol. 37/2-4. Elsevier; 2008

7. Covens P, Berus D, Vanhavere F, Caveliers V. The introduction of automated dispensing and injection during PET procedures: a step in the optimisation of extremity doses and whole-body doses of nuclear medicine staff. Radiat Prot Dosimetry. 2010;140:250-8.

8. Rimpler A, Barth I. Beta radiation exposure of medical staff and implications for extremity dose monitoring. Radiat Prot Dosimetry. 2007; $125: 335-9$

9. Kemerink GJ, Franssen R, Visser MG, Urbach CJ, Halders SG, Frantzen MJ, et al. Hard beta and gamma emissions of 124I. Impact on occupational dose in PET/CT. Nuklearmedizin 2011;50 (6). [Epub ahead of print].

10. Aubert B, Guilabert N, Lamon A, Richard M. Which protection against radiation for new protocols of internal radiotherapy by Yttrium 90? Proceedings of the 6th European ALARA Network Workshop "Occupational Exposure Optimisation in the Medical Field and Radiopharmaceutical Industry", Madrid. 23-25 October 2002, pp 47-9.

11. Coulot J, Ricard M. Radiation protection against yttrium 90: comparison between measurements and Monte-Carlo calculations. 50th Annual Meeting of the Society of Nuclear Medicine, New Orleans. 21-25 June 2003.

12. Chéa M, Donadille L, Trompier F. Etude des performances des protège-seringues utilisés dans un service de médecine nucléaire pour procéder à des injections de radiopharmaceutiques marqués à 1'yttrium 90. IRSN Report DRPH/SDE, no. 2005-28, 2005.

13. IAEA, Radiation Protection of Patients (RPOP).Training material. https://rpop.iaea.org/RPOP/RPoP/Content/AdditionalResources/ Training/1_TrainingMaterial/index.htm. Accessed 27 Oct 2011. 